\title{
Influência da vacinação sobre o nível de infecção estafilocócica da glândula mamária de vacas leiteiras submetidas a desafios naturais*
}

\author{
Vaccination influence on staphylococcal infection level of the mammary \\ gland in dairy cows submitted to natural challenge
}

\author{
José Eurico de Faria, ${ }^{\star *}$ Marcelo Souza Pinto, ${ }^{\star \star}$ Renato Dale ${ }^{\star \star}$, Belmiro Zamperlini ${ }^{\star \star *}$
}

\begin{abstract}
Resumo
O presente trabalho teve como objetivo avaliar a eficiência da vacinação com vacina celular anti-Staphylococcus aureus, contendo adjuvante sulfato dextran e óleo mineral, na prevenção e controle de mastite estafilocócica e comparar os resultados desta vacina com outra de mesma composição, porém contendo apenas o sulfato dextran como adjuvante. Foram utilizadas 15 vacas leiteiras de raça holandesa, pura ou mestiça, com 58 quartos mamários funcionais, de propriedade localizada no município de Viçoșa, Minas Gerais, Brasil. Os animais foram vacinados, por via intramuscular, no início do período "seco" e, novamente, um mês após a primeira vacinação. Os níveis de infecção dos quartos mamários foram avaliados em três períodos distintos: final da lactação (antes da primeira vacinação), semana do parto e um mês após o parto. Estes níveis de infecção não diferiram estatisticamente $(p>0,05)$, pelo teste do Qui-quadrado, com os verificados nos mesmos períodos em animais vacinados com vacina semelhante, porém sem o adjuvante óleo mineral (Faria,1995). As taxas de cura e de nova infecção de quartos mamários foram, respectivamente, de $84,62 \%$ e $15,56 \%$ durante o período "seco" e de $50 \%$ e $10,53 \%$ durante o primeiro mês de lactação. Os resultados mostraram uma maior predominância do efeito curativo sobre o preventivo, fato evidenciado quando comparado ao que acontece com o uso da vacina contendo somente o sulfato dextran como adjuvante, conforme relatado por Faria (1995).
\end{abstract}

Palavras-chave: mamite bovina; vacinas; Staphylococcus aureus.

\begin{abstract}
The purpose of this study was to evaluate the efficacy of the anti-Staphylococcus aureus vaccine, containing dextran sulfate and mineral oil in the prevention and control of the mammary gland Staphylococcal infection. The results were compared with those of a similar vaccine containing only dextran sulfate as adjuvant. Fifty eitgh mammaries quarters from fifteen Holstein or Holstein $X$ Zebu dairy cows from a herd of a farm located in Viçosa, M.G, Brazil were vaccinated, by intramuscular injection, at the beginning of dry period, receiving a booster injection four weeks later. The levels of mammary quarter infection were evaluated at three different periods: end of lactation (before the first vaccination), parturition week and one month after the parturition. The infection levels during the three periods studied did not show any significant difference $(p>0,05)$ between the group treated with this vaccine and the group studied by Faria (1995), using similar vaccine, without mineral oil. The rates of cure and new intramammary infection (IMI) were, respectively, $84,62 \%$ and $15,56 \%$, during the dry period and, 50,00\% and $10,53 \%$ during the first month of lactation. The results showed that this vaccine is more effective in eliminating IMI than in preventing new IMI. This was more evident when results were compared to those obtained using vaccine containing only dextran sulphate, as reported by Faria (1995).
\end{abstract}

Keywords: bovine mastitis; vaccines; Staphylococcus aureus.

\section{Introdução}

A mamite é considerada a principal doença que afeta os rebanhos leiteiros em todo o mundo e aquela que proporciona as maiores perdas econômicas na exploração leiteira. Estima-se que mundialmente as perdas anuais pela doença são da ordem de 35 bilhões de dólares e, na Argentina, de aproximadamente 221 milhões por ano (Giraudo et al.,1997). A queda na produção de leite é responsável pela maior parcela do total das perdas, visto que a diminuição é substancial nas vacas infectadas. Incluem-se, ainda, gastos com medicamentos, leite descartado, serviços veterinários, descarte prematuro de animais e diminuição no valor comercial dos animais infectados. Isso sem contar as perdas ocasionadas à indústria de laticínios devido à queda na qualidade do produto em função das alterações na sua composição química, a crescente preocupação com os resíduos de antibiótico no leite, além dos possíveis riscos à saúde pública.

\footnotetext{
${ }^{*}$ Apoio CNPq e FAPEMIG.

** Departamento de Veterinária da UFV. CEP 36571-000 - Viçosa, MG, Brasil.

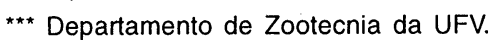


No Brasil, e na maioria dos países, o Staphylococcus aureus é a causa predominante da mamite bovina (Waage et al., 1999). Os estafilococos, especialmente $S$. aureus, apresentam grande resistência aos tratamentos convencionais, o que evidencia a importância do desenvolvimento de novas pesquisas sobre o controle da infecção estafilocócica na glândula mamária.

Programas de vacinação são designados para potencializar o sistema imune do animal a responder a um estímulo antigênico específico. Vacinas para mamite elicitam um recrutamento de neutrófilos e macrófagos para o sítio de infecção, além de estimular a produção de anticorpos específicos. A imunização pode aumentar a concentração de neutrófilos através da liberação de mediadores da inflamação (citocinas) por populações de linfócitos antígeno-específicos. Anticorpos específicos são requeridos para a opsonização da bactéria e para promover a fagocitose por macrófagos e neutrófilos. Além de servir como opsoninas, os anticorpos ainda neutralizam toxinas bacterianas, interferem nos mecanismos de adesão da bactéria e induzem a lise do patógeno invasor. Tanto o número de neutrófilos quanto a concentração de anticorpos são baixos na glândula mamária saudável, sem infecção. Assim, protocolos de imunização, que são capazes de potencializar estes componentes bactericidas importantes, podem contribuir para um controle efetivo da mamite (Sordillo et al., 1997).

A vacinação contra mamite tem sido avaliada com o intuito de aumentar o título de anticorpos específicos no sangue e no leite, promovendo imunidade por aumentar a fagocitose das bactérias invasoras e a neutralização das toxinas (Nickerson et al., 1993 ; Nordhaug et al., 1994b ; Sordillo et al., 1997).

As vacinas são utilizadas com o objetivo de eliminar infecções intramamárias crônicas, prevenir o estabelecimento de novas infecções e/ou reduzir a freqüência e severidade da doença clínica. Porém, as vacinas que são freqüentemente avaliadas aparentam não reduzir consistentemente a incidência de novas infecções ou eliminar infecções crônicas. No entanto, estudos recentes apontam que as vacinas têm reduzido efetivamente a incidência de mamite clínica (Tyler et al., 1993 ; Sordillo et al., 1997).

Muitas tentativas têm sido realizadas visando prevenir a mamite por Staphylococcus aureus através da vacinação. Muitos destes estudos usaram sistematicamente bacterinas derivadas do cultivo de culturas in vitro (Brock et al., 1975 ; Yoshida et al., 1984 ; Pankey et al., 1985 ; Watson, 1992 ; Nickerson et al., 1993 ; Nordhaug et al., 1994a ; Nordhaug et al., 1994b ; Faria, 1995 ; Watson et al., 1996 ; Calzolari et al. 1997 ; Giraudo et al., 1997)

Evidências sugerem que as toxinas estafilocócicas também são importantes por causarem danos ao tecido hospedeiro e promover o crescimento bacteriano. Estudos têm mostrado que novilhas vacinadas com vacinas de $S$. aureus, formuladas para estimular anticorpos antipseudocápsula estafilocócica, contendo a e b-toxina, reduziram a taxa de novas infecções intramamárias e ainda, a infecção foi de menor duração que no grupo não vacinado (Sears et al., 1990 apud Sordillo et al., 1997). Os autores relatam que a eficácia deste novo tipo de formulação de vacinas ainda não foi avaliada em condições naturais mas, Faria (1995), em experimento realizado no Brasil, mostrou o comportamento de uma bacterina contendo antígenos pseudocapsulares, em vacas submetidas a desafios naturais.

Giraudo et al. (1997), avaliando uma bacterina contendo $S$. aureus e Streptococcus sp., causadores de mamite, em noviIhas, sob condições naturais, verificaram uma redução das infecções intramamárias por $S$. aureus de $18,8 \%$ para $6,7 \%$, nas novilhas vacinadas antes do parto (uma dose 8 e outra 4 semanas antes do parto) e para $6 \%$ no grupo vacinado pósparto (uma dose 1 semana após e outra 5 semanas pós-parto). Tal efeito ainda foi mantido por, no mínimo, 6 meses e não se observou efeito sobre a contagem de células somáticas ou sobre o nível de infecção estreptocócica. Os autores atribuem a eficácia da vacina estudada, sobre a infecção estafilocócica, à alta concentração $\left(1 \times 10^{10} \mathrm{UFC} / \mathrm{ml}\right)$ de antígenos bacterianos e polissacarídeos capsulares adotada.

Ao comparar a eficácia de uma interleucina-2 bovina recombinante (rBolL-2) como adjuvante numa vacina com Staphylococcus aureus frente a um desafio experimental, DeRosa e Sordillo(1997) observaram que todos os animais, incluindo o grupo controle que recebeu salina como adjuvante, exibiram aumento similar nos títulos séricos de anticorpos antipseudocápsula de $S$. aureus e que os animais tratados com salina mostraram um aumento significante de anticorpos anti-a-toxina, se comparado com o grupo tratado com rBolL-2. No entanto, os níveis lácteos de anticorpos antipseudocápsula, nestes, foram superiores ao controle. Os autores concluíram que, embora os animais tratados com rBolL-2 tenham exibido um aumento na produção de citocinas pela estimulação antigênica, a eficácia deste protocolo de vacinação foi inferior ao comparado com a proteção oferecida pelo tratamento com salina como adjuvante.

Em trabalho semelhante ao aqui realizado, Faria (1995) avaliou a eficiência de uma vacina celular de Staphylococcus aureus adjuvada pelo sulfato dextran na prevenção e controle da infecção estafilocócica na glândula mamária em rebanho bovino leiteiro. A vacina, então, reduziu o nível de infecção na semana do parto, mas não um mês após, e foi mais eficaz na prevenção que na eliminação das infecções da glândula mamária durante o período "seco".

Este estudo teve como objetivos avaliar a eficiência da vacina celular adjuvada com sulfato dextran e óleo mineral na prevenção e controle de mamite estafilocócica e comparar os resultados desta vacinação com aqueles de trabalho feito anteriormente (Faria, 1995) em que a vacina possuía apenas o sulfato dextran como adjuvante, e ainda prolongar os efeitos da vacinação sobre a redução do nível de infecção durante o período "seco," para o período de lactação.

\section{Material e métodos}

O experimento foi desenvolvido nas dependências do Laboratório de Bacteriologia do Setor de Medicina Veterinária Preventiva do Departamento de Veterinária, Universidade Federal de Viçosa.

Animais: Foram avaliados 58 quartos mamários de 15 vacas de raça holandesa, puras ou mestiças de holandesa com zebu, com idade e número de partos que variaram de 3 a 8 anos (média de 5 anos) e 1 a 4 crias (média de 2 crias/vaca), respectivamente, de propriedade localizada no município de Viçosa, Minas Gerais, Brasil. Os animais foram introduzidos 
no experimento no final da lactação, ocasião em que se coIheram as primeiras amostras de leite. A duração do período "seco" foi, em média, de 96 dias.

Colheita das amostras de leite: As amostras de leite para exames bacteriológicos foram colhidas antes da ordenha, em frascos estéreis, tomando-se os devidos cuidados de higiene e antissepsia. Os úberes e tetas foram lavados e desinfectados com produtos à base de iodo e secados com toalha de papel descartável. Os dois primeiros jatos de leite foram colhidos na caneca de fundo escuro e o terceiro no frasco para o exame bacteriológico. Duas amostras de leite foram colhidas na última semana da lactação, obedecendo um intervalo de aproximadamente 24 horas entre cada coIheita. Na lactação seguinte, mais duas amostras de leite foram colhidas, sendo uma dentro da primeira semana pósparto e outra um mês após o parto.

Isolamento e identificação do estafilococo: As amostras de leite foram inicialmente pré-incubadas a $37^{\circ} \mathrm{C}$, por seis a dezoito horas e, após, fazendo-se uso de uma alça de platina, foram estriadas em ágar sangue base adicionado de $5 \%$ de sangue desfibrinado de carneiro. Após, então, as placas foram incubadas a $37^{\circ} \mathrm{C}$, por 24-48 horas (NATIONAL MASTITIS COUNCIL,1969). As culturas que apresentaram características macroscópicas e microscópicas próprias de estafilococos foram submetidas às provas complementares visando sua identificação presuntiva. A classificação presuntiva das principais espécies de estafilococos se baseou, em parte, em algumas das provas agrupadas em tabela por Kloos e Schleifer (1986), que são: Hemólise em ágar sangue; Prova da catalase (Holmberg, 1973); Prova da coagulase (Schalm et al., 1971); Reação da desoxirribonuclease (DNase) conforme Kowalski (1977); Fermentação do manitol ; Crescimento anaeróbio em meio líquido de tioglicolato de Brewer; Reação de Voges-Proskawer, como descrita em Bier (1985).

Vacina e Vacinoterapia: A amostra de Staphylococcus aureus utilizada na produção da vacina foi isolada de amostras de leite de vacas com mamite clínica ou subclínica e identificada, de acordo com os critérios mencionados anteriormente. Esta amostra, então considerada patogênica, com hemólise alfabeta, foi cultivada e posteriormente inativada com formalina a $1 \%(\mathrm{v} / \mathrm{v})$ e concentrada para $10^{10}$ bactérias $/ \mathrm{ml}$, adjuvada com sulfato dextran (P.M. 500.000) na proporção de $50 \mathrm{mg} / \mathrm{ml}$ de vacina (Watson, 1988 ; Faria, 1995) e óleo mineral na proporção de $18 \%$. A vacina foi aplicada em duas doses de dois mililitros, por via intramuscular, na coxa, em lados alternados, com intervalo de 30 dias.

Tratamento experimental: As 15 vacas foram vacinadas na primeira semana do período "seco" e novamente um mês após a primeira vacinação.

Avaliação: Foi feita conforme Faria (1995): os quartos mamários foram considerados como infectados no momento da secagem da lactação, quando foi isolado Staphylococcus aureus em pelo menos uma das duas amostras de leite colhidas na última semana de lactação. Essa metodologia, em infecção experimental, demonstrou uma probabilidade de $93,5 \%$ de se isolar o agente (Sears et al., 1990). O tratamento foi considerado eficaz quando os quartos infectados com Staphylococcus aureus na última semana da lactação, mostraram-se sem infecção logo após o parto. O tratamento foi considerado ineficaz quando os quartos infectados com
Staphylococcus aureus, na última semana da lactação, mostravam os mesmos patógenos logo após o parto. Os quartos sem infecção por Staphylococcus aureus na última semana da lactação e infectados na primeira semana pós-parto foram considerados como infectados no período "seco"(nova infecção). Os quartos sem infecção por Staphylococcus aureus na última semana da lactação e na primeira semana pósparto e infectados no primeiro mês de lactação foram considerados como infectados durante a lactação.

Análise estatística: os resultados obtidos neste experimento, quanto ao número de quartos mamários infectados e não infectados por Staphylococcus aureus, foram analisados e comparados aos obtidos por Faria (1995), através do teste do Qui-quadrado ao nível de $5 \%$ de significância.

\section{Resultados e discussão}

Tanto no momento da secagem da lactação, quanto na semana do parto e no período de um mês após o parto, não ocorreram diferenças estatisticamente significativas $(p>0,05)$ em relação aos quartos infectados e não infectados com Staphylococcus aureus, entre o grupo vacinado com sulfato dextran e óleo mineral (Tabela 1) e o vacinado apenas com sulfato dextran (Tabela 2).

Tabela 1: Níveis de infecção de quartos mamários, por Staphylococcus aureus, no momento da secagem da lactação, na semana e um mês após o parto, em vacas submetidas ao tratamento com vacina celular adjuvada com sulfato dextran e óleo mineral, em rebanho da Zona da Mata de Minas Gerais - 1997

\begin{tabular}{cccc}
\hline \multirow{2}{*}{ Períodos } & \multicolumn{3}{c}{ Número e percentual de quartos mamários } \\
\cline { 2 - 4 } & Infectados & $\begin{array}{c}\text { Não } \\
\text { infectados }\end{array}$ & Total \\
\hline Secagem & $13(22,4 \%)$ & $45(77,6 \%)$ & $58(100,0 \%)$ \\
Semana do parto & $9(15,5 \%)$ & $49(84,5 \%)$ & $58(100,0 \%)$ \\
1 mês pós-parto & $11(19,0 \%)$ & $47(81,0 \%)$ & $58(100,0 \%)$ \\
\hline
\end{tabular}

Tabela 2: Níveis de infecção de quartos mamários, por Staphylococcus aureus, no momento da secagem da lactação, na semana e um mês após o parto, em vacas submetidas ao tratamento com vacina celular adjuvada com sulfato dextran, em rebanho da Zona da Mata de Minas Gerais - 1994

\begin{tabular}{cccc}
\hline & \multicolumn{2}{c}{ Número e percentual de quartos mamários } \\
\cline { 2 - 4 } Períodos & Infectados & $\begin{array}{c}\text { Não } \\
\text { infectados }\end{array}$ & Total \\
\hline Secagem & $6(10,91 \%)$ & $49(89,09 \%)$ & $55(100,0 \%)$ \\
Semana do parto & $6(10,91 \%)$ & $49(89,09 \%)$ & $55(100,0 \%)$ \\
1 mês pós-parto & $7(12,96 \%)$ & $47(87,04 \%)$ & $54(100,0 \%)$ \\
\hline
\end{tabular}

Fonte: Faria (1995).

As taxas de cura e de nova infecção de quartos, durante o período "seco", foram respectivamente: $84,62 \%$ e $15,56 \%$ para os animais vacinados com a vacina celular adjuvada com sulfato dextran e óleo mineral (Figura 1), enquanto que essas 
mesmas taxas verificadas por Faria (1995), em animais que receberam o tratamento com a vacina que possuía apenas o sulfato dextran como adjuvante (Figura 2) foram, respectivamente, de $33,33 \%$ e 4,08\%.

Embora a taxa de cura do grupo tratado com vacina adjuvada com sulfato dextran e óleo mineral $(84,62 \%$ - Figura 1$)$ tenha sido muito superior à do grupo tratado com a vacina adjuvada apenas com sulfato dextran (33,33\% - Figura 2), conforme Faria (1995), nota-se que a taxa de nova infeção foi também muito superior $(15,56 \%$ - Figura 1) à encontrada por Faria (1995), 4,08\% (Figura 2). Mesmo assim, não foi possível encontrar diferença estatística $(p>0,05)$ entre os efeitos curativo e preventivo das duas vacinas, em todo o período de estudo, quando analisadas pelo teste do Qui-quadrado. Também não houve diferença estatisticamente significativa $(p>0,05)$ nos níveis de infecção com Staphylococcus aureus, no período seco e na lactação, entre as duas vacinas.
A taxa de cura verificada neste experimento (Figura 1) foi respectivamente mais alta e próxima às encontradas por Nickerson et al. (1991), que estudaram uma bacterina comercial $(73 \%)$ e uma vacina com proteína $A(83 \%)$.

A taxa de cura e de nova infeçção dos quartos, durante o primeiro mês de lactação foi, respectivamente, de $50 \%$ e $10,53 \%$ (Figura 1). Nos animais submetidos ao tratamento com vacina adjuvada somente com o sulfato dextran foram, respectivamente, de $25 \%$ e $8,51 \%$ (Figura 2), conforme Faria (1995).

A taxa de nova infecção durante a lactação (10,53\%) foi menor que a ocorrida durante o período "seco" (15,56\%) (Figura 1). A taxa de cura de infecção dos quartos mamários foi maior durante o período "seco" $(84,62 \%)$ do que à ocorrida durante o primeiro mês de lactação (50\%).

Embora tenha havido redução de 6,9\% no nível de infecção na semana do parto (Tabela 1), os níveis de infecção dos períodos da secagem e semana do parto não diferiram significativamente $(p>0,05)$.

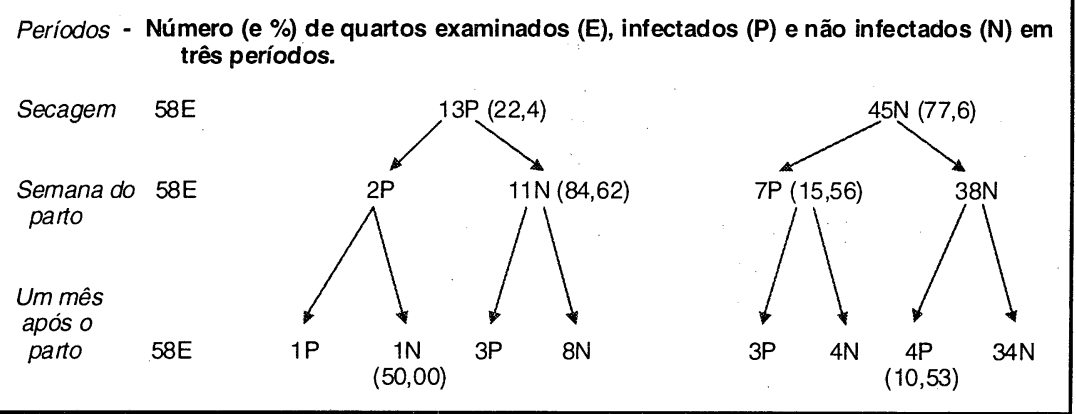

Figura 1: Dinâmica da infecção de quartos mamários, por Staphylococcus aureus, do momento da secagem da lactação até um mês pós-parto da lactação seguinte, em vacas submetidas ao tratamento com vacina celular adjuvada com sulfato dextran e óleo mineral, em rebanho de Minas Gerais - 1997.

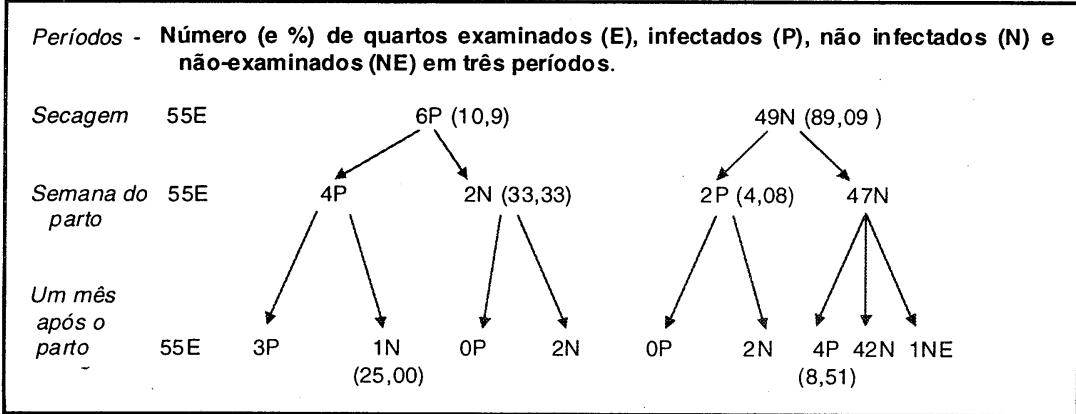

Figura 2: Dinâmica da infecção de quartos mamários, por Staphylococcus aureus, do momento da secagem da lactação até um mês pós-parto da lactação seguinte, em vacas submetidas ao tratamento com vacina celular adjuvada com sulfato dextran, em rebanho da Zona da Mata de Minas Gerais - 1994.

Fonte: Faria (1995).
A vacina mostrou eficácia ao aumentar a taxa de cura, porém não reduziu a taxa de nova infecção. Esses resultados mostram um comportamento diferente do observado com a vacina adjuvada somente com sulfato dextran, que apresentou melhor eficácia na redução da taxa de nova infecção do que da taxa de cura.

Não se verificou redução do nível de infecção durante o primeiro mês de lactação, embora nesse período a taxa de cura (50\%, Figura 1) tenha sido superior à taxa de cura de animais vacinados com a vacina adjuvada somente com sulfato dextran (25\%, Figura 2).

A vacina celular anti-Staphylococcus aureus, adjuvada de sulfato dextran e óleo mineral, aplicada por via intramuscular, não provoca reação adversa no local da aplicação.

Verificou-se, na vacina em questão, uma maior predominância do efeito curativo sobre o preventivo, fato esse evidenciado quando comparado ao que acontece com o uso da vacina contendo somente sulfato dextran como adjuvante, conforme relatado por Faria (1995).

Os resultados apontam para a necessidade de se aprofundar os estudos sobre esta vacina, principalmente no que diz respeito ao tipo de imunidade que suscita, para esclarecer a importância de diferentes adjuvantes em influenciar as taxas de cura e de nova infeção.

\section{Referências bibliográficas}

BIER, O. (ed.) Microbiologia e Imunologia. 24. ed . São Paulo : Melhoramentos, 1985.

BROCK, J. H., STEEL, E. D., REITER, B. The effect of intramuscular and intramammary vaccination of cows on antibody levels and resistance to intramammary infection by Staphylococcus aureus. Res. Vet. Sci., v.19, n. 2, p.152-158, 1975.
CALZOLARI, A., GIRAUDO, J. A., RAMPONE, H. et al. Field trials of a vaccine against bovine mastitis. 2. Evaluation in two commercial dairy herds. J. Dairy Sci., v. 80, n. 5, p. 854-858, 1997.

DeROSA, D. C., SORDILLO, L. M. Efficacy of a bovine Staphylococcus aureus vaccine using interleukin-2 as an adjuvant. Zentralbl Veterinarmed (B)., v. 44, n. 10, p. 599-607, 1997.

FARIA, J. E. Prevenção e controle de infecção estafilocócica da glândula mamária pela vacinação elou Antibioticoterapia associada 
ao dimetilsulfóxido (DMSO). 1995. $101 \mathrm{f}$. Tese (Doutorado) - Escola de Veterinária da Universidade Federal de Minas Gerais.

GIRAUDO J. A., CALZOLARI, A. RAMPONE, H. et al. Field trials of a vaccine against bovine mastitis. Evaluation in heifers. J. Dairy Sci., v. 80, n. 5, p. 845-853, 1997.

HOLMBERG, O. Staphylococcus epidermidis isolated from bovine milk. Acta Vet. Scand. (supll. 45).144 p. 1973.

KLOSS, W. E., SCHLEIFER, K. H. Staphylococcus. In: SNEATH, P.H.A. (ed.) Bergey's Manual of Systematic Bacteriology. V.2. Baltimore : Williams \& Wilkins, 1986, p.1013-1035.

KOWALSKI, J. J. Microbial agents and bovine mastitis. J. Am. Vet.Med. Assoc., v.170, n.10, pt 2, p.1175-1177, 1977.

NATIONAL MASTITIS COUNCIL. Microbiological procedures for the diagnosis of bovine mastitis. Washington : University of $\mathrm{New}$ Hampshire Press, 1969.

NICKERSON, S. C., OWENS, W. E., BODDIE, R. L. Effect of a Staphylococcus aureus bacterin on serum antibody, new infection, and mammary histology in nonlactanting dairy cows. J. Dairy Sci., v. 76, n. 5, p.1290-1297, 1993.

. Progress in the development of a vaccine to control mastitis. Louis. Agric., v. 34, n. 4, p. 20-22, 1991.

NORDHAUG, M. L., NESSE, L. L., NORCROSS, N. L. et al. A field trial with an experimental vaccine against Staphylococcus aureus mastitis in cattle. 1. Clinical parameters. J. Dairy Sci., v. 77, n. 5, p. 1267-1275, 1994a.

A field trial with an experimental vaccine against Staphylococcus aureusmastitis in cattle. 2. Antibody response. J. Dairy Sci., v. 77, n. 5, p.1276-1284, 1994b.
PANKEY, J. W., BODDIE, N. T., WATTS, J. L. et al. Evaluation of protein $A$ and a commercial bacterin as vaccines against Staphylococcus aureus mastitis by experimental challenge. J. Dairy Sci., v. 68, n. 3, p. 726-731, 1985.

SEARS, P. M., SMITH, B. S., ENGLISH, P. B. et. al. Shedding pattern of Staphylococcus aureus from bovine intramammary infection. $J$. Dairy Sci., v. 73, n. 10, p. 2785-2789, 1990.

SHALM, O. W., CARROLL, E. J., JAIN, N. C. (ed.) Bovine Mastitis. Philadelphia : Lea \& Febiger, 1971.

SORDILLO, L. M., SHAFER-WEAVER, K., DeROSA, D. Immunobiology of the mammary gland. J. Dairy Sci., v. 80, n. 8, p. 1851-1865, 1997.

TYLER, J. W., CULLOR, J. S., RUFFIN, D. C. Immunization and immunotherapy for mastitis. Vet. Clin. North. Am. Food Anim. Pract., v. 9, n. 3, p. 537-549, 1993.

WAAGE, S., MORK, T., ROROS, A. et al. Bacteria associated with clinical mastitis in dairy heifers. J. Dairy Sci., v. 82, n. 4, p. 712719,1999 .

WATSON, D. L. Vaccination against experimental Staphylococcal Mastitis in ewes. Res. Vet. Sci, v. 45, n. 1, p. 16-21, 1988.

Vaccination against experimental Staphylococcal Mastitis in dairy heifers. Res. Vet. Sci., v. 53, n. 3, p. 346-353, 1992.

McCOLL, M. L., DAVIES, H. I. Field trial of staphylococcal mastitis vaccine in dairy herds: clinical, subclinical and microbiological assessments. Aust. Vet. J., v. 74, n. 6, p. 447-450, 1996.

YOSHIDA, K.; ICHIMAN, Y.; NARIKAWA, S. et al. Staphylococcal capsular vaccine for preventing mastitis in two herds in Georgia. J. Dairy Sci., v. 67, n. 3, p. 620-627, 1984. 